\title{
Ocular Morbidities In a Tertiary Hospital In Southwest Nigeria: Pattern and Visual Impact
}

\author{
Omodele O.A Jagun*, Merry Godwin, Anthony Betiku, Ubong Fingesi, Olushola S Olajide \\ Ophthalmology Unit, Babcock University Teaching Hospital, Ilishan-Remo. Ogun State, Nigeria. \\ Corresponding author*
}

\begin{abstract}
Ocular mobidities cause vision impairment with varing impact on the vision and quality of life of patients. This study aims to determine the pattern of eye diseases and its visual implication in patients as a means to reduce the burden of visual impairment and blindness. A retrospective study of 700 participants with $259(37.0 \%)$ males and $441(63 \%)$ females. The age range of the participants was between 3 to 88 years [average $=40.21 \pm 23.78$ years]. Participants within the 16-30 years age group were the most prevalent $(30.2 \%)$.

Refractive errors were the most prevalent [49.7\%] ocular morbidities, followed by Conjuctivitis (14.2\%), Cataracts (10.2\%), Glaucoma (8.7\%) and Pseudophakia/Aphakia $(4.2 \%)$. Of those with conjunctivitis, Allergy accounted for $69.5 \%$ (89 participants). There was a $69 \%$ improvement in vision after treatment amongst those with mild and moderate visual impairment, while those that were blind also improved by $16.9 \%$ after treatment. The most prevalent ocular morbidities seen in this study were similar to those reported in previous African studies and prompt treatment of these conditions remarkable reduced the prevalence of visual impairment and blindness.
\end{abstract}

Keywords: Ocular, Morbidities, Visual, Impact, Nigeria.

\section{INTRODUCTION}

$\mathrm{O}$ cular morbidity is a frequent cause of hospital presentation worldwide and its global pattern is influenced by racial, geographic, socioeconomic, and cultural factors [1]. Nutritional factors and ocular infections are more prevalent in developing countries, while hereditary factors, developmental disease, and the consequences of prematurity are more prevalent causes in countries with better standards of living and health care services [1].

Ocular mobidities cause vision impairment (VI) and the World Health Organization (WHO) statistics conducted in 2020 noted that the global prevalence of VI ( distant and near) was about 1 billion [2]. The global distant VI were mainly due to refractive error (123.7 million), Cataract (65.2 million), Glaucoma (6.9 million), Corneal opacity (4.2 million), Diabetic retinopathy (3 million), Trachoma (2 million) while near VI was caused by unaddressed Presbyopia (826 million)[2]. Eighty percent of these ocular mobidities were also noted to be either preventable, treatable or curable causes of VI[1]. Distant VI can be measured with the Snellen's chart and has been categorized into Mild (6/12-6/18), Moderate (6/18-6/60), Severe (6/60-3/60) and blindness (worse than $3 / 60)$ according to ICD 11[2].
In Africa, many cultural barriers to the uptake of ophthalmic services in orthodox hospital have been documented [3,4] and many patients are known to seek orthodox eye care only when traditional eye medications have failed [5-7]. The commonest causes of ocular morbidity in Nigerian hospitals have been Cataracts, Refractive errors, Glaucoma and Conjuctivitis [8-11].These mobidities were also similar to those documented in some African Countries like Ethopia[11] and Sudan[12] . Ocular mobidities have varing impact on the vision and quality of life of patients and its especially worse in those with severe VI and blindness[13,14].

This study aims to determine the pattern of eye diseases and its visual implication in patients at the Babcock University Teaching Hospital as a means to reduce the burden of visual impairment and blindness.

\section{METHODS}

It is a retrospective study, which looked at available consecutive case records of New patients who presented at the Ophthalmic Department of Babcock University Teaching Hospital [BUTH], Ilishan-Remo, Ogun State, Nigeria over a period of one year between January 2019 to December 2019. BUTH is located next to a University community and serve the University students and staff, neighbouring communities and states.

A total of 1450 new patients were found in the register and 700 were selected by systematic random sampling picking every third case in the register.

The demographic profile such as age, sex, occupation of the patients were noted. The presenting and best corrected visual acuity and definitive diagnosis documented after due examinations and investigations were also retrived.

Statistical analysis was done using SPSS 21. Descriptive statistics were used in summarizing the data and Pearson's chi-square statistical method was used to determine statistical significance of association between categorical variables at 5\% probability level.

\section{RESULT}

The total number of selected cases for the study period were 700; out of which 259 (37.0\%) were males and 441 (63\%) females giving a female to male ratio of $2: 1$. The age range of the patients was between 3 to 88 years, with an average of 
$40.21 \pm 23.78$ years. Participants within the 16-30 years age group were the most prevalent $(30.2 \%)$ [Table 1 ].

Table-1: Age and sex distribution of participants

\begin{tabular}{|c|c|c|c|c|c|c|}
\hline Age [Years] & \multicolumn{2}{|c|}{ Male } & \multicolumn{2}{c|}{ Female } & Total & \\
\hline & NO. & $(\%)$ & NO. & $(\%)$ & NO. & $\%$ \\
\hline$\leq 15$ & 17 & 2.4 & 85 & 12.1 & 102 & 14.3 \\
\hline $16-30$ & 74 & 10.6 & 137 & 19.6 & 211 & 30.2 \\
\hline $31-45$ & 36 & 5.1 & 67 & 9.6 & 103 & 14.7 \\
\hline $46-60$ & 42 & 6.0 & 73 & 10.4 & 115 & 16.4 \\
\hline$>60$ & 90 & 12.9 & 79 & 11.3 & 169 & 24.2 \\
\hline TOTAL & 259 & & 441 & & 700 & 100 \\
\hline
\end{tabular}

Table 2 shows a comparison between the presenting VA and the VA after correction with spectacles or equivalents.

Table 2: Presenting and best corrected visual acuity [VA] of participants

\begin{tabular}{|c|c|c|c|c|}
\hline $\begin{array}{c}\text { Visual Acuity } \\
\text { [VA] }\end{array}$ & Presenting Va & $\begin{array}{c}\text { Best } \\
\text { Corrected Va }\end{array}$ & \\
\hline $6 / 5$ & Number & $\%$ & Number & $\%$ \\
\hline $6 / 6$ & 147 & 21.0 & 216 & 30.8 \\
\hline $6 / 9$ & 138 & 19.7 & 16 & 2.3 \\
\hline $6 / 12$ & 58 & 8.3 & 10 & 1.4 \\
\hline $6 / 18$ & 48 & 6.8 & 22 & 3.1 \\
\hline $6 / 24$ & 50 & 7.0 & 8 & 1.1 \\
\hline $6 / 36$ & 38 & 2.1 & 20 & 2.9 \\
\hline $6 / 60$ & 15 & 5.6 & 3 & 0.4 \\
\hline $3 / 60$ & 50 & 7.1 & 41 & 5.9 \\
\hline$<3 / 60$ & 68 & 10.1 & 59 & 8.4 \\
\hline TOTAL & 700 & & 700 & \\
\hline
\end{tabular}

Table 3: Occupation of participants

\begin{tabular}{|c|c|c|}
\hline Occupation/Designation & Number & $\%$ \\
\hline Students & 265 & 37.9 \\
\hline Traders & 104 & 14.8 \\
\hline Professionals & 85 & 12.1 \\
\hline Civil servants & 64 & 9.1 \\
\hline Retiree & 60 & 8.6 \\
\hline Unemployed & 46 & 6.6 \\
\hline Artisans & 22 & 3.1 \\
\hline Not documented & 54 & 7.7 \\
\hline TOTAL & 700 & 100 \\
\hline
\end{tabular}

Figure 1: Pattern of Ocular morbidities amongst participants. OHT=Ocular Hypertension, $\mathrm{P} / \mathrm{A}=$ Pseudophakia/Aphakia,

$\mathrm{RE}=$ Refractive errors.

\section{DISCUSSION}

The most prevalent ocular morbidities recorded in this study were refractive errors, conjunctivitis, cataracts and Glaucoma which was similar to previous studies in southern and northern Nigeria[8-11]. This was also similar to the findings in studies carried out in other African countries like Ethiopia[12], Sudan[13] and South Africa[16]. However, according to the global causes of ocular morbidities, conjunctivitis especially the allergic variant which seems to be common in Africa is not listed as a prevalent condition by the WHO[1]. This high prevalence may be because allergic conjunctivitis is said to be more prevalent in warm climates and amongst Afro-carribeans[17]. Cornea scarring from measles, trachoma, Vit A deficiency, eye injuries etc which is the forth commonest global cause of ocular morbidity[1,18] was not 
found to be significant in our study. The prevalence of Pseudophakia $(4.2 \%)$ in our study was very low and this may because those recording the diagnosis in our register only documented the most prominent morbidity the patients had and it could also be because nearly $60 \%$ of the participants were less than 46 years, and cataract surgery rate is expected to be rare or very low before this age.

The age group 16-30 years had the highest representation (30.2\%) in this study and these were mainly students (37.9\%) which also accounted for the highest group of participants seen as shown in Table 3. This is due to the location of the teaching hospital within a University

setting. Even though the hospital is a tertiary centre, the prevalence of Refractive errors and Conjuctivitis were still very high due to the poor Primary eye care structure in the State and Country, which makes all patients even with minor complains present at the tertiary eye centers.

There was a significant improvement in vision after treatment of these ocular morbidities as participants who presented with mild VI [6/12-6/18] showed a remarkable improvement of $69 \%$ by reducing from 106 to 33 participants [Table 2]. Those with moderate VI [6/18-6/60] also improved by about $69 \%$ by reducing from 106 to 31 participants, those with severe VI [6/60-3/60] were also noted to improve by $18 \%$ from 50 to 41 participants and those that where blind [worse than $3 / 60$ ] also improved by about $16.9 \%$ by decreasing from 71 to 59 participants. Those with normal vision of $6 / 5,6 / 6$ also increased by $40.7 \%$ from 235 to 521 participants [Table 2]. This is in keeping with findings by Oladigbolu et al that prompt presentation and treatment of ocular morbidities leads to reduction in VI and blindness[11] with eventual improvement in the quality of life of the participants[14]. Delayed presentation and treatment would however lead to worsen vision and blindness[18].

\section{CONCLUSION}

The most prevalent ocular morbidities seen in this study were similar to those reported in previous African studies but Allergic conjunctivitis which was the second most prevalent in this study was not documented as a common global cause of ocular morbidity. This study also impliies that prompt treatment of these eye conditions remarkable reduces the prevalence of visual impairment and blindness.

\section{CONFLICT OF INTEREST}

None.

\section{REFERENCES}

[1] Global Initiative for the Elimination of Avoidable Blindness: action plan 2006-2011. WHO. (Accessed 02/08/21)

[2] Causes of blindness and vision impairment in 2020 and trends over 30 years, and prevalence of avoidable blindness in relation to VISION 2020: The Right to Sight: An analysis for the Global Burden of Disease study.(2021). Lancet Glob Health., 9: e144-60.

[3] Olusanya, BA., Ashaye, AO., Owoaje, ET., Ajayi, BG., Bayeroju, AM., (2018). Reasons for non-utilization of eye care services among adults in a rural West African population. Afr. J. Med. Sc., 47: 79-84.

[4] Okoye, RS., Bell, L., Papadopoulos, I., (2018). Barriers to accessing good eye care services in Nigeria: A focus on Anambra State. JNOA., 20(1):30-37.

[5] Eze, BI., Chuka-Okosa, CM., Uche, JR., (2009). Traditional eye medicine use by newly presenting ophthamic patients to a teaching hospital in Southeast Nigeria: Sociodemographic and clinical correlates. BMC Complement Altern Med., 9 (40).

[6] Jaya, Y., Masanganise, R., (2014). The Prevalent type and effect of traditional eye medicine use among newly presenting patients at Sekum Kaguvi hospital eye unit in Harare, Zimbabwe. Central African Journal of Medicine., 60 (2).

[7] Abraham, EG., Ekanem, US.,(2016). Pattern of traditional eye medicine use as seen in a tertiary hospital-University of Uyo teaching hospital experience. Ibom Med. J., 4(1):29-32.

[8] Hassan, MB., Olowokere, SA., Adeleke, NA., Akinleye, CA., Adepoju, EG., (2013). Patterns of presentations at a free eye clinic in an urban state hospital. Niger J Clin Pract., 16:145-8.

[9] Adeoti, CO., Akanbi, A., Abioye-Kuteyi, EA., Akintoye, IO., Egbawale, BE., (2020). Pattern of eye diseases in a tertiary hospital in Osogbo. AJRROP., 3(4): 1-8.

[10] Chukwuka, IO., Pedro-Egbe, CN.,Ejimadu, CS., Cookey, SAH., Onua, AA., Briggs, DE.,(2019). Pattern of eye disorders at the Ophthalmology clinic of a tertiary health faculty in the Niger-delta region: The implications for preventive Ophthalmology. OR., 10(1):1-5.

[11] Oladigbolu, K., Abah, ER., Chinda, D., Anyebe, EE.,(2012). Pattern of eye diseases in a University service clinic in Northern Nigeria. Nigeria Journal of Medicine., 21 (3): 334-337.

[12] Ademe, S., Edmealem, A., (2020). Pattern of ocular diseases among patients attending ophthalmic outpatient department: A cross sectional study. Int J Clin Exp Ophthamol, 4:049-053.

[13] Lakho, KA., Mohammed-Ali, AB., (2015). Pattern of eye diseases at a tertiary eye hospital in Sudan ( Makali Eye Hospital, Khartoum). Albasar Int J Ophthalmol., 3: 15-8.

[14] Rishita, N., Bindiganavale, RS., Praveen, KN., Jill, EK., Sannapeneni, K., Gullapalli, NR., Ravi, T., (2006). Impact of impaired vision and eye disease on quality of life in Andha Predesh. Investigative Ophthalmology \& Visual Science., 47: 4742-4748.

[15] Onabolu, OO., Jagun, OO., Ebonhor, M.,(2019). The impact of blindness in the socioeconomic lives of young adults in South western Nigeria. Int J Cur Res Rev., 11 (19): 4-8.

[16] Verwey, VF., Mahomed, S., (2020). Burden of eye conditions at a specialized eye hospital in Kwazula-Natal, South Africa. Afr. Vision Eye Health., 79(1): a518.

[17] Malu, KN.(2014). Allergic conjunctivitis in Jos-Nigeria. Journal of the Nigeria Medical Association., 55 (2): 166-170.

[18] CBM Nigeria-Improving access of communities to child eye health services through the intervention of PHC workers in Nigeria.

www.iapb.org/new/cbm-Nigeria-improving-acces-of-community-t o-child-eye-health-2019. [Accessed 10/8/2021] 